\title{
Clinical and radiologic rebound after discontinuation of natalizumab therapy in a highly active multiple sclerosis patient was not halted by dimethyl-fumarate: a case report
}

\author{
Francesco Patti, Carmela Leone and Mario Zappia*
}

\begin{abstract}
Background: The evidence on the use of the oral dimethyl-fumarate after the discontinuation of treatment with natalizumab in people with Multiple Sclerosis is still little. Natalizumab discontinuation may induce the recurrence or rebound of the clinical and neuroradiological disease activity. Currently no therapeutic approach has been established to abolish disease reactivation and rebound after natalizumab interruption.

Case Presentation: We describe a case of a 21 -year-old woman affected from a highly active relapsing-remitting Multiple Sclerosis who developed a clinical and radiological rebound 5 months after the last infusion of natalizumab, while she was being treated with dimethyl-fumarate $240 \mathrm{mg}$ twice daily. She had received a bridge "therapy" with Cyclophosphamide before staring dimethyl-fumarate.

Conclusion: We report on this case to stimulate further research to establish whether new current and future drugs available for multiple sclerosis are able to halt the disease rebound after the natalizumab interruption.
\end{abstract}

Keywords: Multiple sclerosis, Natalizumab discontinuation, Dimethyl-fumarate, Clinical rebound, Radiologic activity, Switching therapy

\section{Background}

Natalizumab (NAT), a specific a4-integrin antagonist blocking lymphocytes transmigration across the blood-brain barrier, is a second-line treatment of active relapsingremitting (RR) multiple sclerosis (MS). The benefit of reduction in relapse rate, disability progression and Magnetic Resonance Imaging (MRI) lesions load has to be weighed against the risks of adverse events [1]. Which is mainly related to the rare but serious progressive multifocal leukoencephalopathy (PML); longer treatment duration increases the risk of this adverse event $[2,3]$. After NAT discontinuation, MRI and clinical disease activity gradually return to the pre-treatment levels [2], sometimes even a rebound

\footnotetext{
*Correspondence: m.zappia@unict.it

Department of Medical Sciences, Surgicals and Advanced Technologies G.F. Ingrassia, Section of Neuroscience, University of Catania, Via Santa Sofia 78,
} 95123, Catania, Italy

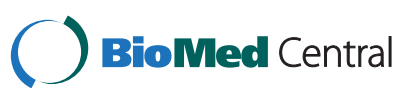

(c) 2015 Patti et al. Open Access This article is distributed under the terms of the Creative Commons Attribution 4.0 International License (http://creativecommons.org/licenses/by/4.0/, which permits unrestricted use, distribution, and reproduction in any medium, provided you give appropriate credit to the original author(s) and the source, provide a link to the Creative Commons license, and indicate if changes were made. The Creative Commons Public Domain Dedication waiver (http://creativecommons.org/publicdomain/zero/1.0/) applies to the data made available in this article, unless otherwise stated. with a flare-up to a level beyond the pre-NAT treatment level was reported [4-6]. There are no available randomized controlled trials or established guidelines on "what to do after NAT therapy". The RESTORE study showed that disease activity began 12-weeks after NAT-discontinuation and occurred regardless of following "drug holiday", "bridge" therapy or "switch" to an alternative treatment with either glatimarer acetate or interferons [7]. On the contrary, those who continued NAT did not show MRI evidence of new disease activity, suggesting that only NAT can stop the rebound due to NAT-interruption. However, in that study [7], new switching options which are available either currently or in the near future, such as fingolimod, dimethyl-fumarate (DMF), teriflunomide and alemtuzumab were not included. Furthermore, other observational studies were conducted to investigate the effect of fingolimod in preventing disease reactivation after NAT discontinuation 
[8-12]. Among them, five studies showed clearly that early initiation of fingolimod (less than 2 or 3 months after discontinuing NAT) decreases the probability of disease reactivation [8, 10-13], highlighting the importance of an early treatment after NAT withdrawal. Iaffaldano et al. showed a superiority of fingolimod in comparison to interferon beta/glatiramer acetate in controlling disease reactivation after NAT discontinuation in a large sample of real life setting [13]. Preliminary evidences showed both positive $[14,15]$, and negative effect of DMF on minimizing disease activity in persons with MS switching from NAT [16].

To summarize, data about MS rebound occurrences in patients treated with DMF after NAT-discontinuation are not available in literature.

\section{Case presentation}

We report the case of a 21-year-old woman who in August 2011 was diagnosed with RRMS. She had no previous relevant medical conditions, nor family history of immune diseases. The disease onset was on May 2011 with acute cerebellar-related balance problems and spontaneously recovered after 3 weeks (EDSS 1.5). Shortly after the diagnosis, in October 2011, she was enrolled in the DECIDE study (double blind randomized controlled trial with IFNbeta 1a and Daclizumab $150 \mathrm{mg}$ (DAC-HYP). However, she withdrew at early stages from this study (July 2012) due to the occurrence of two MS-relapses, both characterized by bi-ocular diplopia and blurred vision (EDSS 3.0). She completely recovered from this relapse after high dose of i.v. steroids. An MRI scan performed on May 2012 showed important radiological disease activity in the brain (25 T2-weighted and 7 T1-weighted/gadolinium-enhanced lesions) as well as in the spine (9 T2-weitghed and 2 T1weighted/gadolinium-enhanced lesions). In August 2012, she started i.v. NAT $300 \mathrm{mg}$ every 28 days. She was seropositive for JC-virus antibody status. During the 2 years of NAT-treatment, she was free of clinical activity and had a stable disability level (EDSS 1.5). She also underwent serial brain and spine MRI scans every 6 months, which showed no radiological disease activity as shown in Fig. 1. However, after 24 NAT-infusions (August 2014), administration of NAT was interrupted due to the risk of PML.

A single pulse of i.v. cyclophosphamide $750 \mathrm{mg}$ was administered in September 2014. Following this, in October 2014 she was switched to DMF, starting with $120 \mathrm{mg}$ twice-a-day for the first 2 weeks, and then switching to DMF $240 \mathrm{mg}$ twice-a-day. Shortly, after the change of dosage, she started to complain of adverse effects in the region of gastro-intestine, which was mainly characterized by nausea and weight-loss - by January 2015, she lost $15 \mathrm{~kg}$. On $15 / 01 / 2015$, she started to complain of new symptoms characterized by lower limb weakness, dizziness and gait ataxia, followed by bilateral blurred vision, in the absence of fever and other infection signs. When she arrived to our

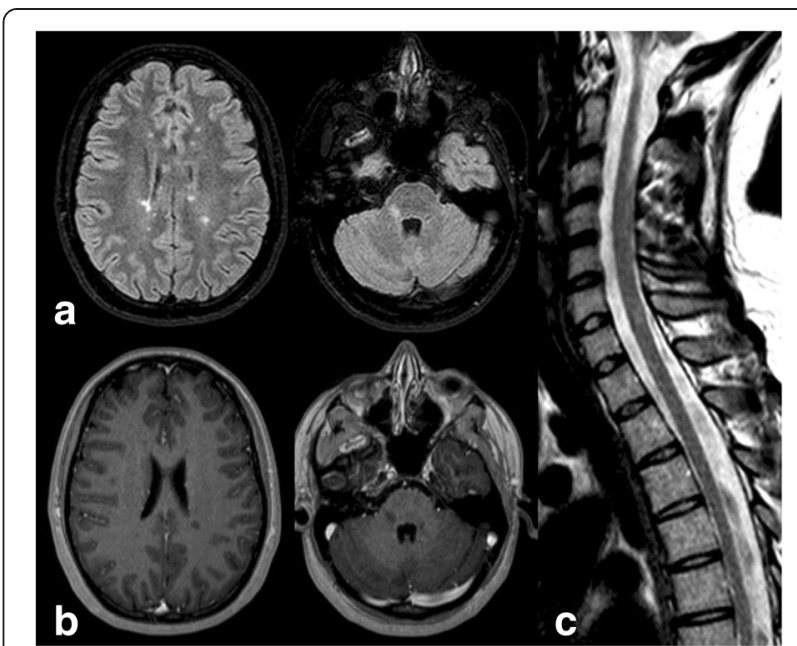

Fig. 1 Axial (a) T2-weighted FLAIR MRI under stable clinical conditions, showing several supratentorial lesions; axial (b) T1-weighted images showing no lesions with ring gadolinium-enhancement, (c) sagittal T2-weighted FLAIR MRI showing two spinal cord lesions

clinic, the neurological examination revealed an EDSS of 6.0 since the patient was able to walk only with a unilateral support for about $100 \mathrm{~m}$. A new brain MRI showed massive progression in T2 lesions and lesions with ring gadoliniumenhancement numbers ( $>20$ gadolinium-enhanced lesions, Fig. 2). A 5-day steroid course was then administered intravenously with great clinical benefit. The MRI performed 1 month later showed a reduction of the number of gadolinium-enhanced lesions in the brain. After one additional month, she recovered completely from the relapse and the neurological examination showed an EDSS of 1.5. On 24/02/2015 she re-started the treatment with NAT. The new JC-virus antibody status index was three.

The young MS patient reported in this case had a severe clinical and radiological rebound after NATinterruption, although she was being treated with DMF, which in turn was started as after a "bridge" therapy with cyclophosphamide.

DMF, an oral treatment for RRMS with immunomodulatory and cytoprotective effects [17], was not able to stop the clinical and MRI activity after NAT-interruption. Recent preliminary results on the effect of DMF on minimizing disease activity related to NAT-interruption have been reported with inconclusive results. Two studies reported on beneficial effects $[14,15]$, and one showed higher disease activity (frequency of patients with relapse) during DMF treatment period compared with NAT period treatment [16]. However, no rebound activity of MS has been shown so far. The AFFIRM, SENTINEL and GLANCE studies showed no rebound [2], but the RESTORE reported a high rate of disease activity after NAT-interruption despite a new drug was started [7]. Since this study proved the superiority of continuing NAT 


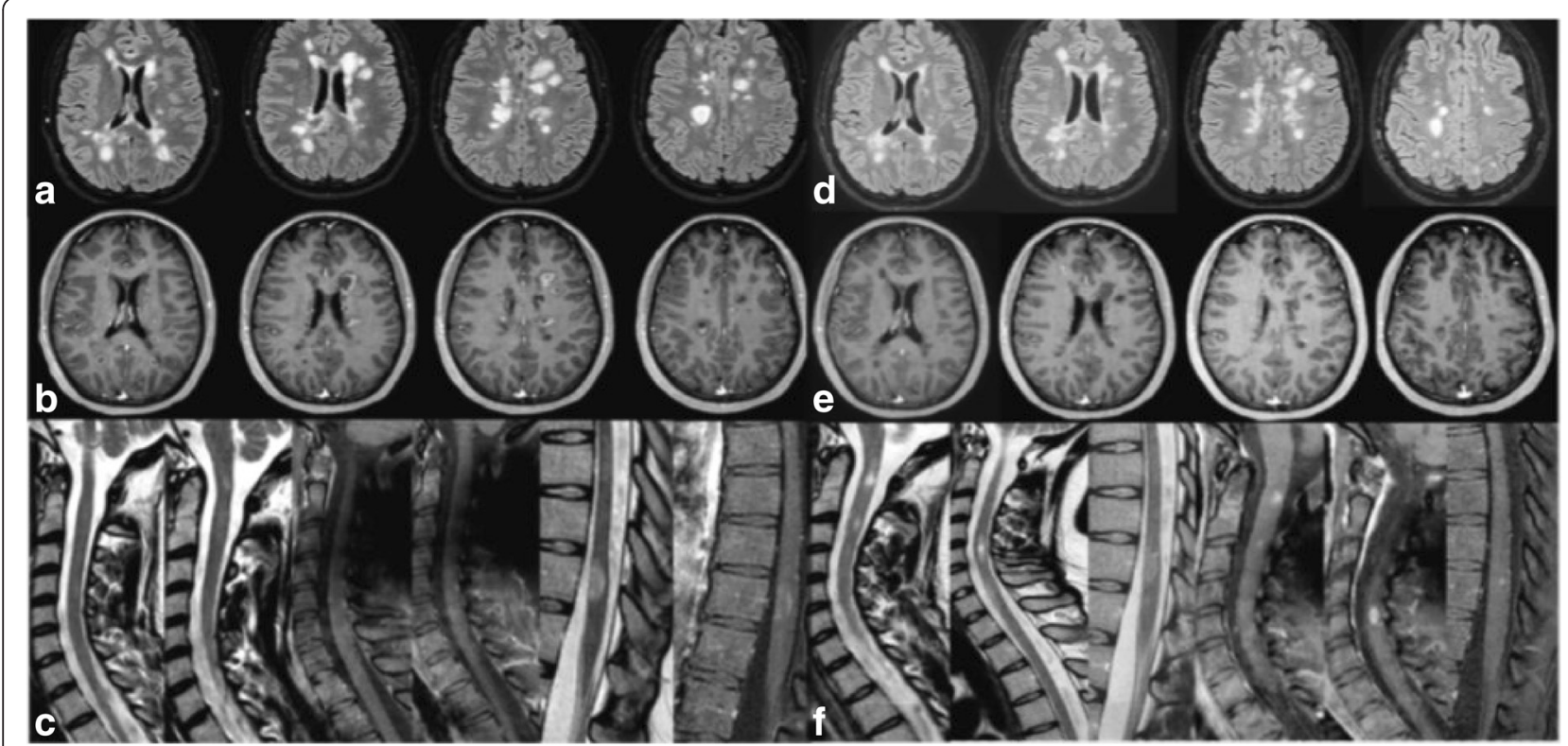

Fig. 2 Axial (a) T2-weighted FLAIR MRI under clinical relapse showing multiple new supratentorial lesions; axial (b) T1-weighted images showing lesions with ring gadolinium-enhancement, (c) sagittal T2-weighted FLAIR MRI showing different spinal cord lesions, one of them with ring gadolinium-enhancement on T1-SPIR weighted image. (d), (e), (f) are the same images repeated after 40 days from high dose of steroids i.v.

in comparison with its interruption despite switching to first-line disease modifying drugs or methylprednisolone, we decided to restart therapy with NAT. Despite her risk of PML, which was likely higher due to the single pulse of immunosuppressant we administered as a bridge therapy. We however started an accurate and strict monitoring of clinical and radiological activity including MRI scans every 3-4 months.

Yet, the best treatment of patients who withdraw from NAT independently from the interruption reasons does not exist. Several strategies applied in clinical practice, such as "bridge" therapy with methylprednisolone, switching to glatimarer acetate or interferon-beta are likely not effective [18]. However, more promising results came from several small $[8,10]$ and large retrospective $[11,12]$ and prospective [13] studies with fingolimod (FTY), but long-term data about its efficacy and safety after NAT are urgently needed. Finally we cannot exclude that the single pulse of cyclophosphamide we used as "bridge" therapy to DMF might have delayed the occurrence of a rebound of another 3 months.

\section{Conclusions}

To summarize, this is the first case of MS rebound after switching from NAT to DMF, independently from the single pulse of cyclophosphamide. Yet, the best therapeutic approach to abolish the disease reactivation after the NATdiscontinuation needs to be found. Considering the narrow time window for the diminishing clinical and biological effects of NAT, we suggest to investigate in depth whether starting the new MS therapy together with the NAT (during i.e. the last three months of the NAT treatment) may be effective.

\section{Ethics}

Any ethics was required for this case presentation, since we are reporting on clinical individual data of a patient followed in our Neurologic Clinic in Catania, Italy.

\section{Consent to publish}

A written informed consent for data publication was obtained from the patient.

\section{Availability of data and materials}

The source documents/files supporting our data are stored in the archive of our clinic and in the iMed $\odot$ software (iMed, Merck Serono SA - Geneva).

\section{Abbreviations}

NAT: natalizumab; RR: relapsing-remitting; MS: multiple sclerosis;

DMF: dimethyl-fumarate; PML: progressive multifocal leukoencephalopathy.

\section{Competing interests}

Dr. Patti has served on the scientific advisory board for Teva, Biogen-Idec, Bayer-Schering, Novartis and has received honoraria as a speaker for Teva, Biogen, Merck-Serono, Bayer-Schering, Genzyme/Sanofi, Novartis. Dr. Leone has received grants for congress from Merk Serono and from the Department GF Ingrassia. Dr. Zappia has received grants from Novartis, Biogen, Merck Serono, Teva e Almirall and has received honoraria from Sanofi-Genzyme.

\section{Authors' contributions}

Carmela Leone drafted the background, wrote the case presentation and discussion sections. Francesco Patti wrote the background section and revised the manuscript critically for important intellectual content. Mario 
Zappia revised the manuscript and gave the final approval of the version to be published. Each author participated sufficiently in the work to take public responsibility for appropriate portions of the content. All authors read and approved the final manuscript.

Received: 28 September 2015 Accepted: 2 December 2015

Published online: 07 December 2015

\section{References}

1. Havrdova E, Galetta S, Hutchinson M, Stefoski D, Bates D, Polman CH, et al. Effect of natalizumab on clinical and radiological disease activity in multiple sclerosis: a retrospective analysis of the Natalizumab Safety and Efficacy in Relapsing-Remitting Multiple Sclerosis (AFFIRM) study. Lancet Neurol. 2009;8: 254-60

2. O'Connor PW, Goodman A, Kappos L, Lublin FD, Miller DH, Polman C, et al. Disease activity return during natalizumab treatment interruption in patients with multiple sclerosis. Neurology. 2011;76:1858-65.

3. Sorensen PS, Bertolotto A, Edan G, Giovannoni G, Gold R, Havrdova E, et al. Risk stratification for progressive multifocal leukoencephalopathy in patients treated with natalizumab. Mult Scler. 2012;18:143-52.

4. West TW, Cree BA. Natalizumab dosage suspension: are we helping or hurting? Ann Neurol. 2010;68:395-9.

5. Rinaldi F, Seppi D, Calabrese M, Perini P, Gallo P. Switching therapy from natalizumab to fingolimod in relapsing-remitting multiple sclerosis: clinical and magnetic resonance imaging findings. Mult Scler. 2012;18:1640-3.

6. Sorensen PS, Koch-Henriksen N, Petersen T, Ravnborg M, Oturai A, Sellebjerg F. Recurrence or rebound of clinical relapses after discontinuation of natalizumab therapy in highly active MS patients. J Neurol. 2014;261:1170-7.

7. Fox RJ, Cree BA, De Seze J, Gold R, Hartung HP, Jeffery D, et al. MS disease activity in RESTORE: a randomized 24-week natalizumab treatment interruption study. Neurology. 2014;82:1491-8.

8. Havla J, Tackenberg B, Hellwig K, Meinl I, Krumbholz M, Seitz F, et al Fingolimod reduces recurrence of disease activity after natalizumab withdrawal in multiple sclerosis. J Neurol. 2013;260:1382-7.

9. Havla J, Gerdes LA, Meinl I, Krumbholz M, Faber H, Weber F, et al. De-escalation from natalizumab in multiple sclerosis: recurrence of disease activity despite switching to glatiramer acetate. J Neurol. 2011;258:1665-9.

10. Laroni A, Brogi D, Milesi V, Abate L, Uccelli A, Mancardi G. Early switch to fingolimod may decrease the risk of disease recurrence after natalizumab interruption. Mult Scler. 2013;19:1236-7.

11. Cohen M, Maillart E, Tourbah A, De Seze J, Vukusic S, Brassat D, et al. Switching from natalizumab to fingolimod in multiple sclerosis: a French prospective study. JAMA Neurol. 2014;71:436-41.

12. Jokubaitis VG, Li V, Kalincik T, lzquierdo G, Hodgkinson S, Alroughani R, et al Fingolimod after natalizumab and the risk of short-term relapse. Neurology. 2014;82:1204-11.

13. laffaldano P, Lucisano G, Pozzilli C, Brescia Morra V, Ghezzi A, Millefiorini E, et al. Fingolimod versus interferon beta/glatiramer acetate after natalizumab suspension in multiple sclerosis. Brain. 2015;138:3275-86.

14. Alvarez E, Vollmer B, Jace B, Corboy J, Vollmer S, Siloou K, et al. Effectiveness of Switching to Rituximab over Fingolimod or Dimethyl Fumarate after Natalizumab in Preventing Disease Activity in Multiple Sclerosis. (P3.288), Neurology 84 (2015)

15. Hadhoum N, Outteryck O, Labreuche J, Cambron M, Ferriby D, Kwiatkowski A, et al. Comparative analysis of oral disease-modifying therapies after natalizumab withdrawal in patients with multiple sclerosis, (P 615), ECTRIMS 2015.

16. Vu N, Moses H, Siriam S, Pawate S. Efficacy of oral Multiple Sclerosis therapies in patients switching from natalizumab (P3.290), Neurology 84 (2015).

17. Linker RA, Gold R. Dimethyl fumarate for treatment of multiple sclerosis: mechanism of action, effectiveness, and side effects. Curr Neurol Neurosci Rep. 2013;13:394

18. Borriello G, Prosperini L, Mancinelli C, Gianni C, Fubelli F, Pozzilli C. Pulse monthly steroids during an elective interruption of natalizumab: a post-marketing study. Eur J Neurol. 2012;19:783-7.

\section{Submit your next manuscript to BioMed Central and we will help you at every step:}

- We accept pre-submission inquiries

- Our selector tool helps you to find the most relevant journal

- We provide round the clock customer support

- Convenient online submission

- Thorough peer review

- Inclusion in PubMed and all major indexing services

- Maximum visibility for your research

Submit your manuscript at www biomedcentral.com/submit 